\title{
Passive and active acoustic properties of a diaphragm at low Mach number
}

\section{Experimental procedure and numerical simulation}

\author{
Hassen Trabelsi* — Nicolas Zerbib** — Jean-Michel Ville* \\ Félix Foucart*
}

* Laboratoire Roberval, Université de Technologie de Compiègne

Centre de Recherches de Royallieu

Rue Personne de Roberval, BP 20529, F-60205 Compiègne cedex

\{hassen.trabelsi, jean-michel.ville,felix.foucart\}@utc.fr

** ESIgroup

20 Rue Fonds Pernant, F-60200 Compiègne cedex

nicolas.zerbib@esi-group.com

\begin{abstract}
In this paper a low noise flow duct facility that performs a multimodal characterization of the passive and active acoustic properties of obstacles in the aero-acoustic conditions of an automotive air conditioning system is presented. The experimental procedure is made of two steps. In the first one the passive data, i.e. the multimodal scattering matrix, is measured with a multi-sources method. In the second step the outgoing modal pressure spectra radiated upstream and downstream by the flow obstacle interaction source is achieved. A numerical simulation of the experiment based on a 3D-Finite Element Method is developed. A very good agreement between the theoretical and experimental results of the no flow scattering matrix of a diaphragm is found. The effect of the flow on the scattering matrix is shown before performing the measurement of the aero-acoustic source characteristics of the diaphragm.

RÉSUMÉ. Dans cet article, un banc d'essai permettant une caractérisation multimodale des propriétés acoustiques passives et actives des obstacles dans les conditions aéroacoustiques d'un système de conditionnement d'air pour automobile est présenté. La procédure expérimentale est réalisée en deux étapes. Dans un premier temps, la composante passive décrite par la matrice de diffusion est mesurée par la méthode multisource. Dans la deuxième étape, les pressions modales rayonnées en amont et en aval par l'interaction entre l'écoulement et l'obstacle sont obtenues. Un modèle éléments finis pour la simulation numérique de l'expérience est développé. Un très bon accord entre les résultats théoriques et expérimentaux de la matrice de diffusion d'un diaphragme sans écoulement est obtenu. L'effet de l'écoulement sur la matrice de diffusion est montré avant de procéder à la mesure de la composante active du diaphragme.
\end{abstract}

KEYWORDS: scattering matrix, flow noise, aero-acoustic source, diaphragm.

MOTS-CLÉS : matrice de diffusion, bruit d'écoulement, source aéroacoustique, diaphragme.

DOI:10.3166/EJCM.20.49-71 @ 2011 Lavoisier, Paris

EJCM - 20/2011. Dynamics of materials, structures and systems, pages 49 to 71 


\section{Introduction}

Sound propagation in duct systems, such as in air conditioning networks, is of importance for engineers working in building, automotive and aeronautical noise control. The sound field in these duct systems depends on the passive and active properties of the elements whose the air conditioning system is made of. The passive properties which determine how the sound is reflected and transmitted through each element are well represented by a scattering matrix formulation and are controlled by the acoustic medium properties and the geometrical or mechanical characteristics of the obstacle. The active properties characterize the acoustic sources due to the interaction between the flow and the obstacle.

Previous works were already conducted to develop methods to measure the passive and active acoustic properties of an obstacle located in a duct. Indeed, Lavrentjev (Lavrentjev et al., 1995) presented a technique for determining the acoustic source data of an axial flow fan in the form of a scattering matrix and a source strength vector. The fan was modeled as an acoustic two-port source, which is defined as a linear and time invariant physical system with one input and one output, so that the study was limited to the plane wave assumption. A year later, Lavrentjev (Lavrentjev et al., 1996) extended the previous method beyond the plane wave region in order to include higher order modes effects resulting in a prediction of the sound field created by the fan at a given acoustic load but only on the upstream region. Recently, Allam (Allam et al., 2006) applied this technique to investigate the sound produced by the interaction between a mean flow and an orifice in a plate at low frequency and for different Mach number in order to collect data for the development of improved methods predicting noise radiated by flow singularities interactions.

The aim of the work presented in this paper is therefore to present a flow duct facility, its equipment and data treatment procedure. This procedure was developed to achieve, for higher order mode propagation condition, measurement of the passive and active acoustic properties of elements which are parts of air conditioning system found in automotive industry. In addition a numerical simulation of the no flow experiment with a diaphragm is developed pointing out the validity of this rig.

This paper starts with a view of the theoretical basis for in duct wave propagation leading to the definition of the scattering matrix. In the second part, the experimental set up and the procedure to measure the multimodal scattering matrix and the source strength level at low Mach number is presented. Then, the model developed for the numerical simulation of the experiment is detailed. Experimental and numerical results of the diaphragm scattering matrix are compared in the no flow case. Finally, the effects of flow on the diaphragm scattering matrix coefficients followed by the experimental pressure vectors produced by the diaphragm flow interaction are discussed. 


\section{Theoretical basis}

\subsection{Expression of the acoustic pressure in a rectangular duct with a uniform mean flow}

Let consider in an infinite length rectangular duct, a uniform mean flow and pressure sound wave vectors incident on the left and right sides of a discontinuity located between $\mathbf{a}_{\mathbf{1}}$ and $\mathbf{b}_{\mathbf{3}}$ (Figure 1).

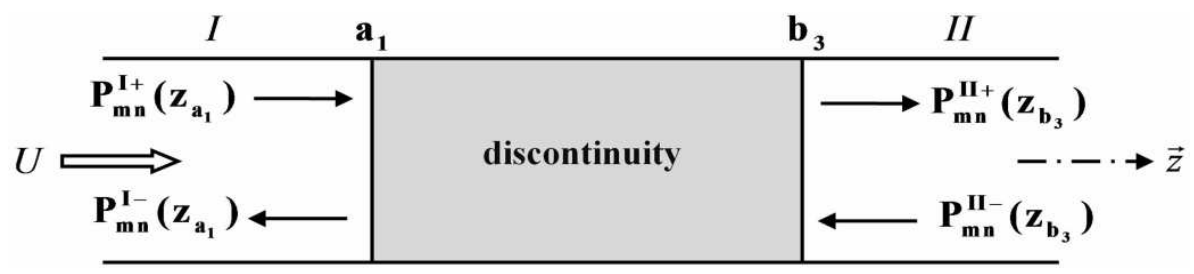

Figure 1. Schematic representation of rectangular duct with uniform mean flow

In the duct sections I and II, the wave equation assuming an axial mean uniform flow velocity $\mathbf{U}$ is written in rectangular coordinates as:

$$
\frac{1}{\mathbf{c}^{2}}\left(\frac{\partial \mathbf{p}}{\partial \mathbf{t}}+\mathbf{U} \frac{\partial \mathbf{p}}{\partial \mathbf{z}}\right)^{2}=\frac{\partial^{2} \mathbf{p}}{\partial \mathbf{x}^{2}}+\frac{\partial^{2} \mathbf{p}}{\partial \mathbf{y}^{2}}+\frac{\partial^{2} \mathbf{p}}{\partial \mathbf{z}^{2}}
$$

Assuming a time dependence in the form of $\mathrm{e}^{\mathrm{i} \omega \mathrm{t}}$ and hard wall duct conditions in $I$ and $I I$, the sound pressure in the duct due a tone of frequency $\omega$ can therefore be expressed as:

$$
\mathbf{P}(x, y, z)=\sum_{m=0}^{\infty} \sum_{n=0}^{\infty}\left(\mathbf{P}_{m n}^{+} \mathbf{e}^{i K_{m n}^{+} z}+\mathbf{P}_{m n}^{-} \mathbf{e}^{i K_{m n}^{-} z}\right) \Phi_{m n}(x, y)
$$

where $\Phi_{\mathbf{m n}}(\mathbf{x}, \mathbf{y})$ are the eigenfunctions of the hard-walled rectangular duct and are computed by the following equation:

$$
\Phi_{m n}(x, y)=\cos \left(n \pi x / L_{x}\right) \cos \left(m \pi y / L_{y}\right)
$$

$\mathbf{L}_{\mathbf{x}}$ and $\mathbf{L}_{\mathbf{y}}$ are, respectively, the width and the height of the duct; the integers $\mathbf{m}$ and $\mathbf{n}$ are, respectively, the vertical and the horizontal wavenumbers $(\mathbf{m}=\mathbf{0}, \mathbf{n}=\mathbf{0}$ is the plane wave). The modal pressure amplitude $\mathbf{P}_{\mathbf{m n}}^{+}$refers to the positive-traveling incident wave that goes with the flow and $\mathbf{P}_{\mathbf{m n}}^{-}$refers to the negative-traveling 
reflected wave that goes against the flow (Figure 1). The axial wave number of mode $(\mathbf{m}, \mathbf{n})$ in the main duct is defined for the positive or negative traveling waves as:

$$
\mathbf{K}_{\mathrm{mn}}^{ \pm}=\mathbf{M k} \mp \sqrt{\mathbf{k}^{2}-\left(\mathbf{1}-\mathbf{M}^{2}\right)\left(\left(\frac{\mathbf{n} \pi}{\mathbf{L}_{\mathrm{x}}}\right)^{2}+\left(\frac{\mathbf{m} \pi}{\mathbf{L}_{\mathrm{y}}}\right)^{2}\right)} /\left(1-\mathbf{M}^{2}\right)
$$

where $\mathbf{k}=\mathbf{2} \boldsymbol{\pi} \mathbf{f} / \mathbf{c}_{\mathbf{0}}$ is the acoustical wave number, $\mathbf{f}$ the frequency, $\mathbf{c}_{\mathbf{0}}$ the speed of sound in air and $\mathbf{M}=\mathbf{U} / \mathbf{c}_{\mathbf{0}}$ the Mach number. The total modal pressure coefficients $\left.\mathbf{P}_{\mathbf{m}} \mathbf{z}\right)$ in the cross sections located at an axial coordinate $\mathbf{z}$ are given by the following relationship:

$$
\mathbf{P}_{\mathrm{mn}}(\mathbf{z})=\mathbf{P}_{\mathrm{mn}}^{+}(\mathbf{z})+\mathbf{P}_{\mathrm{mn}}^{-}(\mathbf{z})
$$

where $\mathbf{P}_{\mathrm{mn}}^{+}(\mathbf{z})$ and $\mathbf{P}_{\mathrm{mn}}^{-}(\mathbf{z})$ are waves traveling in the positive and negative $\mathbf{z}$ directions. They are depicted in regions $I$ and $I I$ by $\mathbf{P}_{m \mathbf{n}}^{I \pm}\left(\mathbf{z}_{\mathbf{a}_{1}}\right)=\mathbf{P}_{\mathbf{m n}}^{I \pm}\left(\mathbf{z}_{0}\right) \mathrm{e}^{\mathbf{i} K_{\operatorname{mn}}^{ \pm}\left(\mathbf{z}_{a_{1}}-\mathbf{z}_{0}\right)}$ and $\mathbf{P}_{m n}^{\mathrm{II}}\left(\mathbf{z}_{\mathbf{b}_{3}}\right)=\mathbf{P}_{m n}^{\mathrm{II}}\left(\mathbf{z}_{0}\right) \mathbf{e}^{\mathrm{i} \mathbf{m}_{\mathrm{mn}}^{ \pm}\left(\mathbf{z}_{\mathrm{b}_{3}}-\mathbf{z}_{0}\right)} \cdot \mathbf{P}_{\mathrm{mn}}^{\mathrm{I}+}\left(\mathbf{z}_{\mathrm{a}_{1}}\right), \mathbf{P}_{\mathrm{mn}}^{\mathrm{I}-}\left(\mathbf{z}_{\mathrm{a}_{1}}\right), \mathbf{P}_{\mathrm{mn}}^{\mathrm{II}+}\left(\mathbf{z}_{\mathrm{b}_{3}}\right)$ and $\mathbf{P}_{\mathrm{mn}}^{\mathrm{II}-}\left(\mathbf{z}_{\mathbf{b}_{3}}\right)$ represent respectively the incident, the reflected, the transmitted and the retrograde modal pressures (Figure 1). $\mathbf{z}_{0}$ is the axial coordinate of the acoustic driver.

\subsection{Scattering matrix definition}

The scattering matrix $[\mathbf{S}]$ of a duct located between $\mathbf{a}_{1}$ and $\mathbf{b}_{3}$ and linked to two rectangular waveguides (region $I$ and $I I$ in Figure 1) is a linear relationship between the incoming pressures vector $\left\{\mathbf{P}^{\text {in }}\right\}_{2 \mathrm{~N}}$ and the outgoing pressures vector $\left\{\mathbf{P}^{\text {out }}\right\}_{2 \mathrm{~N}}$ which can be expressed as:

$$
\left\{\mathbf{P}^{\text {out }}\right\}_{2 \mathrm{~N}}=[\mathbf{S}]_{2 \mathrm{~N} \times 2 \mathrm{~N}} \times\left\{\mathbf{P}^{\text {in }}\right\}_{2 \mathrm{~N}}
$$

where: $\left\{\mathbf{P}^{\text {in }}\right\}_{2 \mathrm{~N}}=\left\langle\mathbf{P}_{00}^{\mathrm{I}+}\left(\mathbf{z}_{\mathbf{a}_{1}}\right), \ldots, \mathbf{P}_{\mathbf{P Q}_{\mathbf{Q}}}^{\mathrm{I}+}\left(\mathbf{z}_{\mathbf{a}_{1}}\right), \mathbf{P}_{00}^{\mathrm{II}-}\left(\mathbf{z}_{\mathbf{b}_{3}}\right), \ldots, \mathbf{P}_{\mathbf{P Q}}^{\mathrm{II}-}\left(\mathbf{z}_{\mathbf{b}_{3}}\right)\right\rangle^{\mathrm{T}}$ and $\left\{\mathbf{P}^{\text {out }}\right\}_{2 \mathrm{~N}}=\left\langle\mathbf{P}_{00}^{\mathrm{I}-}\left(\mathbf{z}_{\mathrm{a}_{1}}\right), \ldots, \mathbf{P}_{\mathbf{P Q}^{\mathrm{I}}}^{\mathrm{I-}}\left(\mathbf{z}_{\mathrm{a}_{1}}\right), \mathbf{P}_{00}^{\mathrm{II}+}\left(\mathbf{z}_{\mathrm{b}_{3}}\right), \ldots, \mathbf{P}_{\mathbf{P Q}}^{\mathrm{II}+}\left(\mathbf{z}_{\mathrm{b}_{3}}\right)\right\rangle^{\mathrm{T}}$.

$\mathbf{N}$ is the number of cut-on modes in both cross-sections located at $\mathbf{z}_{\mathbf{a}_{1}}$ and $\mathbf{z}_{\mathbf{b}_{3}}$. $\mathbf{P}$ and $\mathbf{Q}$ are respectively the vertical and the horizontal wavenumbers associated to the $N^{\text {th }}$ propagating mode. 


$$
[S]_{2 N \times 2 N}=\left(\begin{array}{ll}
{\left[S^{11}\right]_{N \times N}} & {\left[S^{12}\right]_{N \times N}} \\
{\left[S^{21}\right]_{N \times N}} & {\left[S^{22}\right]_{N \times N}}
\end{array}\right)_{2 N \times 2 N}
$$

This matrix, which depicts only the discontinuity, is independent of the upstream and downstream acoustic conditions. The physical meaning of each elementary matrix is as follows:

$-\left[\mathbf{S}^{11}\right]$ is the reflection of the wave coming in the element from the left side,

- $\left[\mathbf{S}^{22}\right]$ is the reflection of the wave coming in the element from the right side,

- $\left[\mathbf{S}^{\mathbf{2 1}}\right]$ is the transmission of the wave coming in the element from the left side,

$-\left[\mathbf{S}^{\mathbf{1 2}}\right]$ is the transmission of the wave coming in the element from the right side.

\section{The experimental setup and data processing}

Any linear and time-invariant acoustic system can be described by a system of equations, which give relations between its output and input state variables (Lavrentjev et al., 1996). If $\mathbf{N}$ modes propagate in the duct which have two ports as illustrated by Figure 2 and if the modal acoustic pressure amplitudes are used as state variables, then the test object can be modeled as an active acoustic $2 \mathbf{N}$-port source.

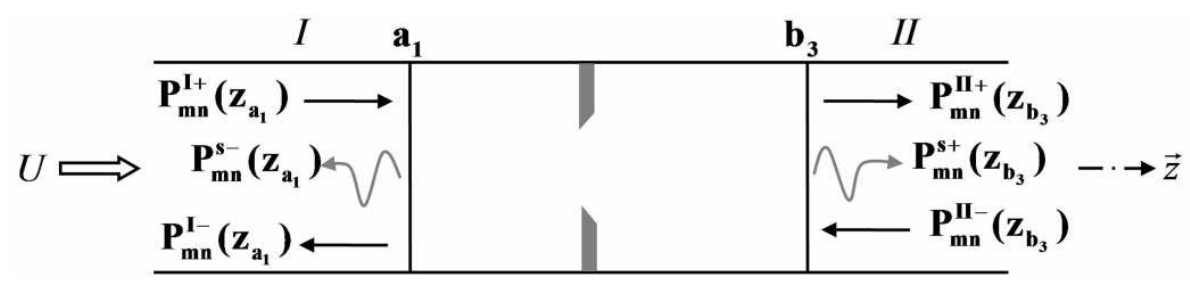

Figure 2. Acoustic waves coming in and out the studied acoustic $2 N$-port source

Using the scattering matrix form, with a vector representing uncorrelated sources in the system, the active acoustic $2 \mathrm{~N}$-port source can be defined as:

$$
\begin{aligned}
& \left\{\begin{array}{l}
\mathbf{P}_{\mathrm{mn}}^{\mathrm{I}-} \\
\mathbf{P}_{\mathrm{mn}}^{\mathrm{II}+}
\end{array}\right\}_{2 \mathrm{~N}}=\underbrace{[\mathbf{S}]_{2 \mathrm{~N} \times 2 \mathrm{~N}}}_{\text {Passive part }} \cdot\left\{\begin{array}{l}
\mathbf{P}_{\mathrm{mn}}^{\mathrm{I}+} \\
\mathbf{P}_{\mathrm{mn}}^{\mathrm{II}-}
\end{array}\right\}_{2 \mathrm{~N}}\{\underbrace{\left\{\begin{array}{l}
\mathbf{P}_{\mathrm{mn}}^{\mathrm{s}-} \\
\mathbf{P}_{\mathrm{mn}}^{\mathrm{s}+}
\end{array}\right.}\}_{2 \mathrm{~N}} \\
& \text { Active part }
\end{aligned}
$$


The experimental procedure intended to characterize the obstacle will be conducted in two steps:

- measurement of the scattering matrix $[\mathbf{S}]$ with flow (see section 3.2 for details),

- measurement of source vector which is deduced from $[\mathbf{S}]$ and from the measurement of the cross-spectrum matrix of the noise produced by the interaction of the flow with the diaphragm. The measurement of this matrix is performed with all microphones signals.

\subsection{Test rig description}

The experimental low noise test rig was developed on the basis of the aeroacoustic specifications found in an automotive air conditioning system in order to measure the passive and active acoustic properties of complex obstacles. It has been installed in the acoustic laboratory of the University of Technology of Compiegne.

The test rig is made of two main parts (Figure 3 and Figure 4):

- the flow generation part composed of:

- centrifugal compressor with frequency variator for controlling the flow speed at the duct inlet (1) and chosen to reach a $20 \mathrm{~m} \cdot \mathrm{s}^{-1}$ mean flow velocity in the test section without any obstacle,

- two mufflers connected with an elbow for reducing fan and flow noises (2)

- the aero-acoustics measurements part composed of:

- flow tranquillizing box for turbulence reduction (3),

- two anechoic terminations, one on the upstream and one on the downstream of the obstacle, used to improve results by reducing the stationary wave ratio (4),

- six rectangular $0.2 \mathrm{~m} \times 0.1 \mathrm{~m}$ cross-section area ducts made of a $0.003 \mathrm{~m}$ thick steel wall:

- a straight duct for flow speed measurement (5). The flow speed was measured upstream of the test section using a Prandtl probe connected to an electronic manometer,

- two source sections, one on the upstream and one on the downstream of the obstacle, with acoustic driver (loudspeaker) mounted in a short side-branch connected to the main duct at $\mathbf{2} \mathrm{N}$ different positions (6),

- two measurement ducts, one on the upstream and one on the downstream of the test object, with 36 microphones (B\&K 1/2") flush mounted on the wall of each $\operatorname{duct}(7)$,

- a test duct in which the obstacle is mounted (8). 


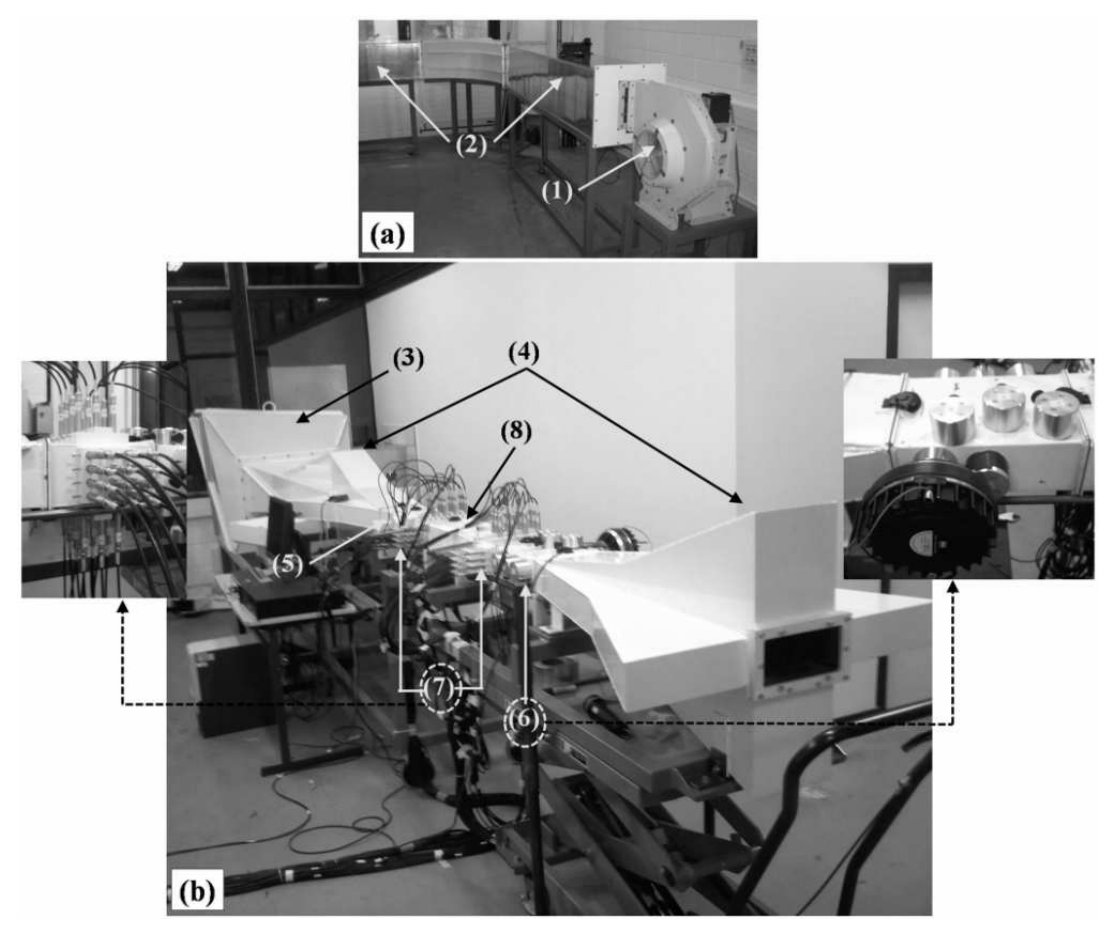

Figure 3. (a) Flow generation facility: (1) Centrifugal compressor, (2) Mufflers; (b) Aero-acoustics measurements facility: (3) Flow tranquillizing box (4) Anechoic terminations, (5) Flow speed measurement duct, (6) Source ducts, (7) Measurement ducts, (8) Test duct

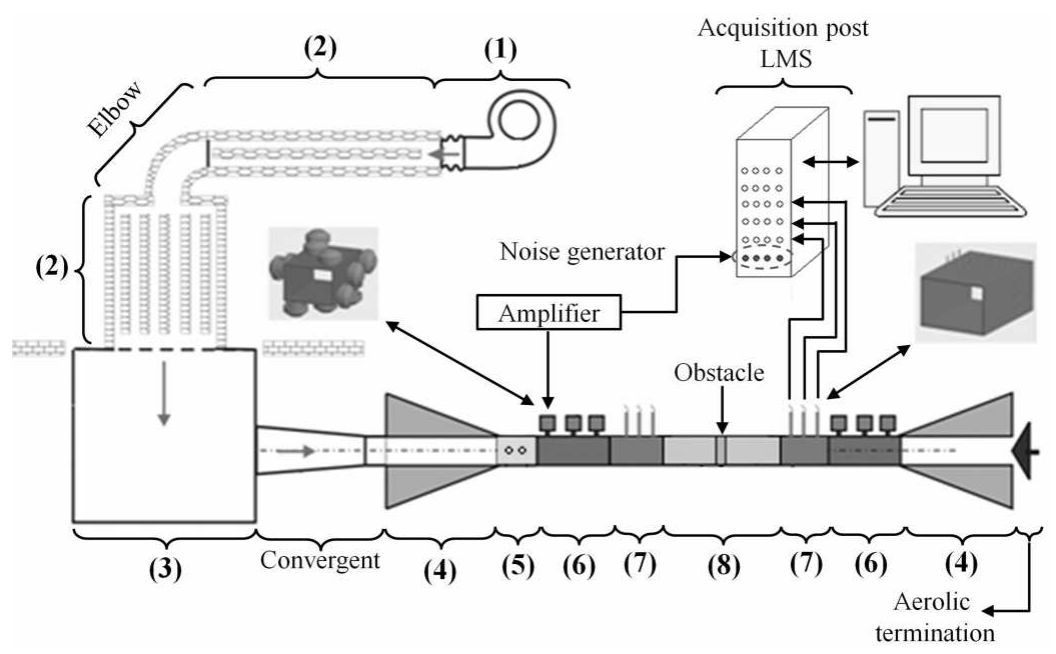

Figure 4. Experimental set up 


\subsection{Multimodal scattering matrix measurement procedure in presence of uniform mean flow}

In order to determine $[\mathbf{S}]$ in presence of flow, measurements are carried out with an acoustic pressure field produced by a loudspeaker which is uncorrelated with the flow diaphragm interaction noise. This leads to avoid the source strength vector $\left\{\mathbf{P}^{\mathrm{s}}\right\}$ in Equation [7] (Lavrentjev et al., 1995) which becomes:

$$
\left\{\begin{array}{l}
\mathbf{P}_{m n}^{I-} \\
\mathbf{P}_{m n}^{I I+}
\end{array}\right\}_{2 N}=[S]_{2 N \times 2 N} \cdot\left\{\begin{array}{l}
P_{m n}^{I+} \\
P_{m n}^{I I-}
\end{array}\right\}_{2 N}
$$

The $(\mathbf{2 N})^{2}$ coefficients of the scattering matrix $[\mathbf{S}]$ are then solutions of the following system deduced from the following equation:

$$
\left[S_{\text {mn,pq }}^{\mathrm{kl}}\right]_{2 N \times 2 N}=\left[\mathbf{P}^{\text {out }}\right]_{2 N \times 2 N} \cdot\left[\mathbf{P}^{\text {in }}\right]_{2 N \times 2 N}^{-1}
$$

where $\mathbf{k}, \mathbf{l}=\mathbf{1 , 2}$ and $\mathbf{m}, \mathbf{n}, \mathbf{p}, \mathbf{q}=\mathbf{1 , 2}, \ldots, \mathbf{N} .\left[\mathbf{P}^{\text {out }}\right]_{2 \mathrm{~N} \times 2 \mathrm{~N}}$ and $\left[\mathbf{P}^{\text {in }}\right]_{2 \mathrm{~N} \times 2 \mathrm{~N}}$ are matrices filled respectively by the incoming and the outgoing modal pressures obtained from $\mathbf{2 N}$ independent external source configurations.

The experimental procedure to measure the multimodal scattering matrix with uniform mean flow is presented in Figure 6. This technique is similar to this developed in the no flow case for cylindrical geometry by Sitel (Sitel et al., 2006) and applied by Taktak (Taktak, 2008) and Poirier (Poirier et al., 2009).

To fill the $\mathbf{2 N}$ columns of $\left[\mathbf{P}^{\text {out }}\right]_{2 \mathbf{N} \times 2 \mathbf{N}}$ and $\left[\mathbf{P}^{\text {in }}\right]_{2 \mathbf{N} \times \mathbf{2 N}}, \mathbf{2 N}$ linearly independent modal pressure distributions are produced by moving the acoustic driver to $\mathbf{N}$ locations on each side of the test duct. For each source configuration, the complex total pressure is deduced from the measurement of the transfer functions between the signal coming out from the power amplifier providing a phase reference and the signals coming out from 72 microphones located in three cross-sections on each side of the test duct (Figure 3 and Figure 5).

To improve the signal to noise ratio a synchronized periodic chirp signal limited to $200-3500 \mathrm{~Hz}$ is generated operating 200 temporal averages before the Fourier transform leading to the transfer function.

At $3500 \mathrm{~Hz}$, a maximum of $\mathbf{N}=10$ propagating modes $(0,0) ;(0,1) ;(0,2) ;(1,0)$; $(1,1) ;(1,2) ;(0,3) ;(1,3) ;(0,4) ;(2,0)$ are considered in the duct. To deduce the modal components of $\left[\mathbf{P}^{\text {out }}\right]_{2 \mathbf{N} \times 2 \mathbf{N}}$ and $\left[\mathbf{P}^{\text {in }}\right]_{2 \mathbf{N} \times 2 \mathbf{N}}$ a modal decomposition method in each section based on the measurement of the total acoustic pressure by twelve 
microphones flush mounted in the duct wall at six cross-sections areas is achieved (Equation [10]).

$$
\left\{\mathbf{P}_{\mathbf{m n}}\left(\mathbf{z}_{\mathbf{i}_{\mathrm{j}}}\right)\right\}_{\mathbf{N}}=[\Psi]_{\mathrm{M} \times \mathbf{N}}^{-1} \cdot\left\{\mathbf{P}\left(\mathbf{z}_{\mathbf{i}_{\mathrm{j}}}\right)\right\}_{\mathrm{M}}
$$

where $\mathbf{i}=\mathbf{a}, \mathbf{b}$ and $\mathbf{j}=\mathbf{1 , 2 , 3} ;\left\{\mathbf{P}_{\mathbf{m n}}\left(\mathbf{z}_{\mathbf{i}_{\mathbf{j}}}\right)\right\}_{\mathbf{N}}$ is the modal total pressure amplitudes vector at each measurement cross-section ; $[\Psi]_{\mathbf{M} \times \mathbf{N}}$ is the eigenfunctions matrix containing eigenfunctions $\Phi_{\mathbf{m n}}$ computed for each mode $(\mathbf{m}, \mathbf{n})$ and at each microphone position; $\left\{\mathbf{P}\left(\mathbf{z}_{\mathbf{i}_{\mathbf{j}}}\right)\right\}_{\mathbf{M}}$ is the total acoustic pressure vector measured at each measurement cross-section; $\mathbf{M}$ is the number of microphones at each measurement cross-section.

Finally the incident and reflected modal vectors at $\mathbf{z}_{\mathbf{a}_{1}}$ and $\mathbf{z}_{\mathbf{b}_{3}}$ are deduced from $\left\{\mathbf{P}_{\mathbf{m n}}\left(\mathbf{z}_{\mathbf{i}_{\mathrm{j}}}\right)\right\}_{\mathbf{N}}$ (Equation [5]) by a separation technique based upon measurement in three cross-sections on each side of the test duct (Figure 5) leading to a surdimensional procedure which avoids inversion problems found when only two cross sections are used (Sitel et al., 2006).

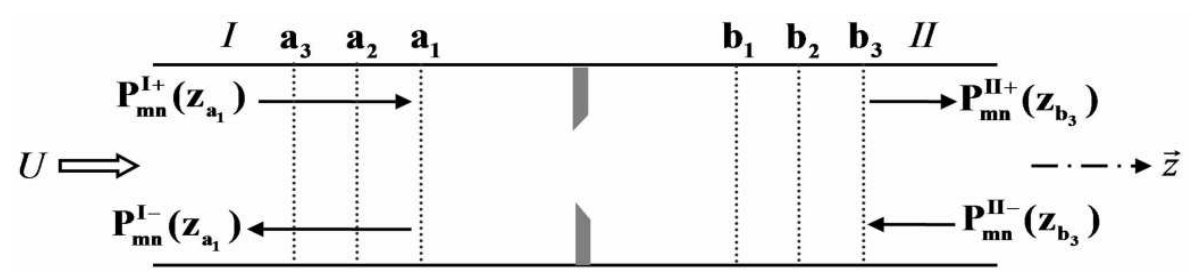

Figure 5. Schematic representation of the sixth measurements cross-sections

\subsection{Source vector measurement}

After the first step, the scattering matrix [S] being measured and the loudspeakers being turned off, measurement of the vector $\left\{\mathbf{P}^{\mathbf{s}}\right\}$ is performed.

To obtain a formulation for both random and periodic types of signals, $\left\{\mathbf{P}^{\mathbf{s}}\right\}$ can be expressed versus the modal cross-spectrum matrix $\mathbf{G}^{\mathbf{S}}$ (Lavrentjev et al., 1995): 


$$
\begin{aligned}
& {\left[\mathbf{G}^{\mathrm{s}}\right]_{2 \mathrm{~N} \times 2 \mathrm{~N}}=\left\{\begin{array}{l}
\mathbf{P}_{\mathrm{mn}}^{\mathrm{s}-} \\
\mathbf{P}_{\mathrm{mn}}^{\mathrm{s}+}
\end{array}\right\}_{2 \mathrm{~N}} \cdot\left\langle\mathbf{P}_{\mathrm{mn}}^{\mathrm{s}-}, \mathbf{P}_{\mathrm{mn}}^{\mathrm{s}+}\right\rangle_{2 \mathrm{~N}}^{*}} \\
& {\left[\mathbf{G}^{\mathbf{s}}\right]_{2 \mathbf{N} \times 2 \mathbf{N}}=\left[\begin{array}{ll}
{\left[\mathbf{G}_{\mathbf{a}_{1} \mathbf{a}_{1}}^{\mathrm{s}}\right]_{\mathbf{N} \times \mathbf{N}}} & {\left[\mathbf{G}_{\mathbf{b}_{3} \mathbf{a}_{1}}^{\mathrm{s}}\right]_{\mathbf{N} \times \mathbf{N}}} \\
{\left[\mathbf{G}_{\mathbf{a}_{1} \mathbf{b}_{3}}^{s}\right]_{\mathbf{N} \times \mathbf{N}}} & {\left[\mathbf{G}_{\mathbf{b}_{3} \mathbf{b}_{3}}^{s}\right]_{\mathbf{N} \times \mathbf{N}}}
\end{array}\right]_{2 \mathbf{N} \times 2 \mathbf{N}}}
\end{aligned}
$$

The superscript "** denotes a complex conjugated quantity.

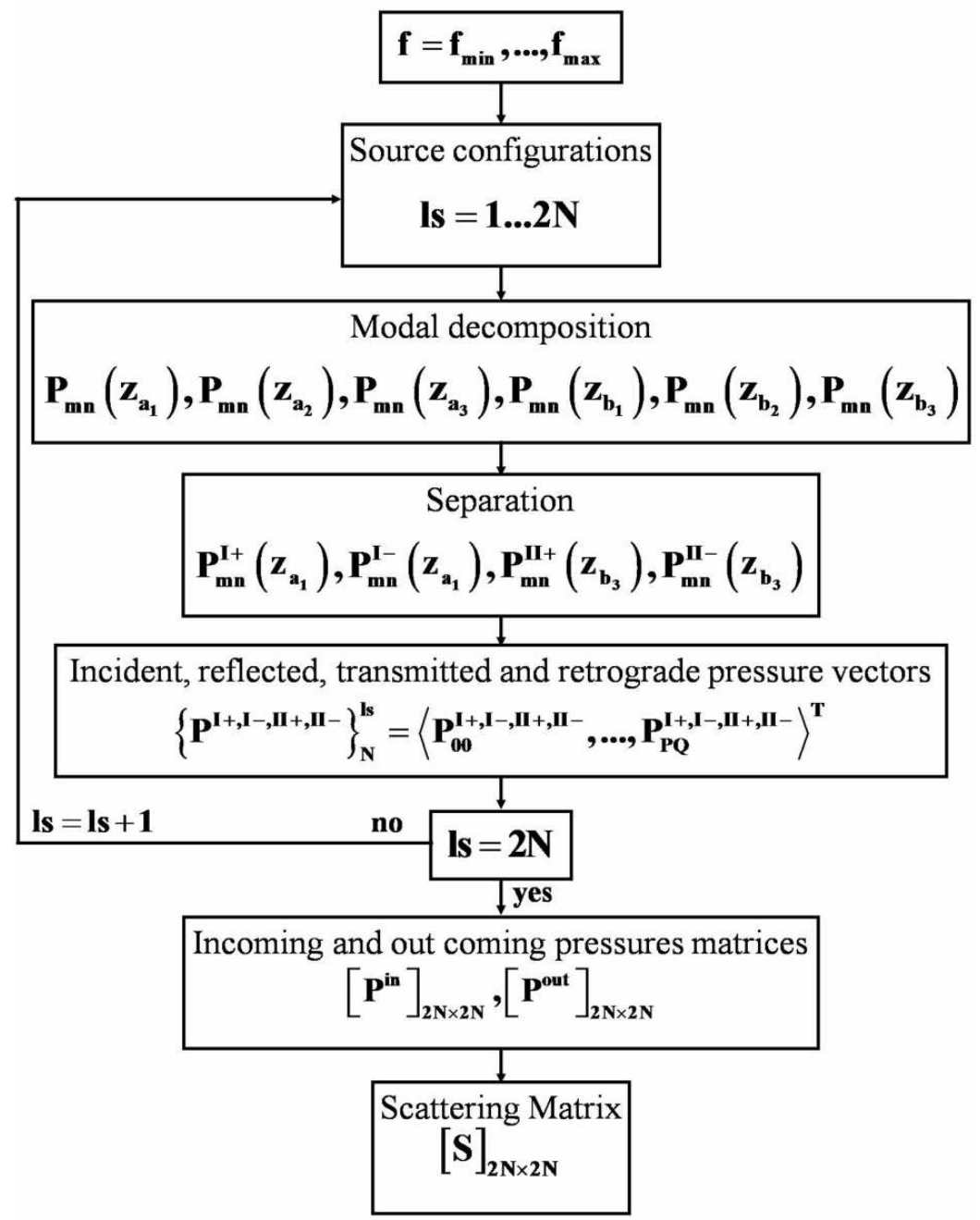

Figure 6. Algorithm flow chart of the scattering matrix measurement 
The source strength vector at the cross-sections $\mathbf{a}_{1}$ and $\mathbf{b}_{\mathbf{3}}$ can be expressed in measurable quantities as shown below.

Indeed, let consider the upstream and the downstream reflection matrices. They are easily deduced from the first step measurement procedure:

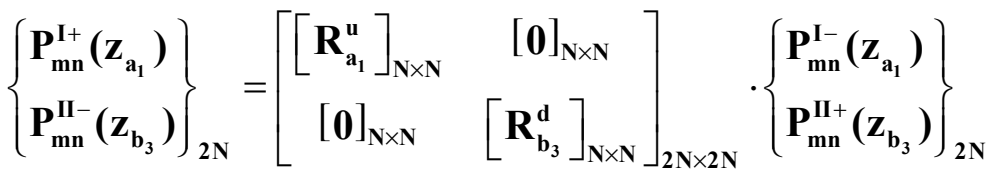

$$
\begin{aligned}
& \left.[\mathbf{R}]_{2 \mathbf{N} \times \mathbf{2 N}}=\left[\begin{array}{cc}
{\left[\mathbf{R}_{\mathbf{a}_{1}}^{\mathbf{u}}\right]_{\mathbf{N} \times \mathbf{N}}} & {[\mathbf{0}]_{\mathbf{N} \times \mathbf{N}}} \\
{[\mathbf{0}]_{\mathbf{N} \times \mathbf{N}}} & {\left[\mathbf{R}_{\mathbf{b}_{3}}^{\mathbf{d}}\right.}
\end{array}\right]_{\mathbf{N} \times \mathbf{N}}\right]_{2 \mathbf{N} \times \mathbf{2} \mathbf{N}}
\end{aligned}
$$

where $\left[\mathbf{R}_{\mathbf{a}_{1}}^{\mathbf{u}}\right]$ represent the reflection matrix of the upstream termination which was measured at $\mathbf{z}_{\mathbf{a}_{1}}$ with the source located upstream of the test duct and $\left[\mathbf{R}_{\mathbf{b}_{3}}^{\mathbf{d}}\right]$ the reflection matrix of the downstream termination measured at $\mathbf{z}_{\mathbf{b}_{3}}$ when the source is mounted downstream the test duct (Figure 3 and Figure 4).

Inserting relationship [12] in Equation [7] gives:

$$
\left\{\begin{array}{l}
\mathbf{P}_{m n}^{s-}\left(\mathbf{z}_{\mathrm{a}_{1}}\right) \\
\mathbf{P}_{m n}^{s+}\left(\mathbf{z}_{\mathbf{b}_{3}}\right)
\end{array}\right\}_{2 N}=[[I]-[S] \cdot[R]]_{2 N \times 2 N} \cdot\left\{\begin{array}{l}
\mathbf{P}_{m n}^{I-}\left(\mathbf{z}_{\mathrm{a}_{1}}\right) \\
\mathbf{P}_{m n}^{I I+}\left(\mathbf{z}_{\mathbf{b}_{3}}\right)
\end{array}\right\}_{2 N}
$$

where $[\mathrm{I}]_{2 \mathrm{~N} \times \mathbf{2 N}}$ represent the identity matrix.

This can be rewritten in terms of the total acoustic pressures at the microphone locations:

$$
\begin{aligned}
& \left\{\begin{array}{l}
\mathbf{P}_{m n}^{I-}\left(\mathbf{z}_{\mathbf{a}_{1}}\right) \\
\mathbf{P}_{m n}^{I I+}\left(\mathbf{z}_{\mathbf{b}_{3}}\right)
\end{array}\right\}_{2 \mathbf{N}}=[\Pi]_{2 N \times 2 M} \cdot\left\{\begin{array}{l}
\mathbf{P}\left(\mathbf{z}_{\mathbf{a}_{1}}\right) \\
\mathbf{P}\left(\mathbf{z}_{\mathbf{b}_{3}}\right)
\end{array}\right\}_{2 M} \\
& {[\Pi]_{2 \mathbf{N} \times \mathbf{2 M}}=\left[\begin{array}{cc}
{\left[[\Psi] \cdot\left([\mathrm{I}]+\left[\mathbf{R}_{\mathbf{a}_{1}}^{\mathbf{u}}\right]\right)\right]^{-\mathbf{1}}} & {[\mathbf{0}]} \\
{[\mathbf{0}]} & {\left[[\Psi] \cdot\left([\mathrm{I}]+\left[\mathbf{R}_{\mathbf{b}_{3}}^{\mathbf{d}}\right]\right)\right]^{-\mathbf{1}}}
\end{array}\right]_{\mathbf{2} \times 2 \mathbf{M}}}
\end{aligned}
$$


where $[\Pi]$ is a matrix that ensures transformation of the modal pressures into total pressures.

From Equations [13] and [14] the vector representing the pressure radiated by the aero-acoustic source upstream and downstream is expressed versus the total pressures measured by the microphones located in both sections by:

$$
\begin{gathered}
\left\{\begin{array}{l}
\mathbf{P}_{\mathrm{mn}}^{\mathrm{s}-}\left(\mathbf{z}_{\mathrm{a}_{1}}\right) \\
\mathbf{P}_{\mathrm{mn}}^{\mathrm{s}+}\left(\mathbf{z}_{\mathrm{b}_{3}}\right)
\end{array}\right\}_{2 \mathrm{~N}}=[\mathbf{C}]_{2 \mathrm{~N} \times 2 \mathrm{M}} \cdot\left\{\begin{array}{l}
\mathbf{P}\left(\mathbf{z}_{\mathrm{a}_{1}}\right) \\
\mathbf{P}\left(\mathbf{z}_{\mathbf{b}_{3}}\right)
\end{array}\right\}_{2 \mathrm{M}} \\
{[\mathbf{C}]_{2 \mathrm{~N} \times 2 \mathrm{M}}=[[\mathrm{I}]-[\mathbf{S}] \cdot[\mathbf{R}]]_{2 \mathrm{~N} \times 2 \mathrm{~N}} \cdot[\Pi]_{2 \mathrm{~N} \times 2 \mathrm{M}}}
\end{gathered}
$$

Finally, Equation [11] is modified and shows that the modal cross-spectrum matrix is deduced from the measurement of the microphone cross-spectrum matrix [G] and from the measurement, during the first step of the procedure, of the scattering matrix $[\mathbf{S}]$ and of the reflection matrices of both terminations $\left[\mathbf{R}_{\mathbf{a}_{1}}^{\mathbf{u}}\right]$ and $\left[\mathbf{R}_{\mathbf{b}_{3}}^{\mathbf{d}}\right]$ :

$$
\begin{aligned}
& {\left[\mathbf{G}^{\mathrm{s}}\right]_{2 \mathbf{N} \times 2 \mathbf{N}} }=[\mathbf{C}]_{2 \mathbf{N} \times 2 \mathbf{M}} \cdot[\mathbf{G}]_{2 \mathbf{M} \times 2 \mathbf{M}} \cdot[\mathbf{C}]_{2 \mathbf{M} \times 2 \mathbf{N}}^{\mathbf{c}} \\
& {[\mathbf{G}]_{2 \mathbf{M} \times 2 \mathbf{M}}=\left[\begin{array}{ll}
{\left[\mathbf{G}_{\mathbf{a}_{\mathbf{a}_{1} \mathbf{a}_{1}}}\right]_{\mathbf{M} \times \mathbf{M}}} & {\left[\mathbf{G}_{\mathbf{b}_{3} \mathbf{a}_{1}}\right]_{\mathbf{M} \times \mathbf{M}}} \\
{\left[\mathbf{G}_{\mathbf{a}_{1} \mathbf{b}_{3}}\right]_{\mathbf{M} \times \mathbf{M}}} & {\left[\mathbf{G}_{\mathbf{b}_{3} \mathbf{b}_{3}}\right]_{\mathbf{M} \times \mathbf{M}}}
\end{array}\right]_{2 \mathbf{M} \times 2 \mathbf{M}} }
\end{aligned}
$$

where the auto- and cross-spectra are formally defined as $\left[\mathbf{G}_{\mathbf{x y}}\right]_{\mathbf{M} \times \mathbf{M}}=\left\{\mathbf{P}_{\mathbf{x}}\right\}_{\mathbf{M}}^{\mathrm{c}} \cdot\left\{\mathbf{P}_{\mathbf{y}}\right\}_{\mathbf{M}}$, and the superscript "ce" denotes a transposed and complex conjugated quantity.

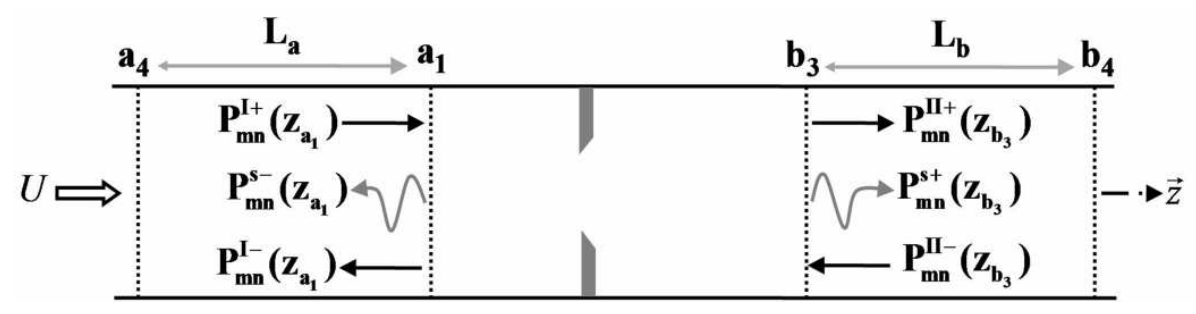

Figure 7. Cross-sections for the source strength vector measurement

In order to avoid flow disturbance on the microphones, Aböm (Aböm et al., 1992) suggested a method based on the measurement of the source strength vector at 
cross-sections far enough from the diaphragm to ensure that the flow disturbance is lower and uncorrelated with the noise produced by the flow diaphragm interaction. Let $\mathbf{L}_{\mathbf{a}}=0.5 \mathrm{~m}$ the distance between $\mathbf{a}_{1}$ with the new cross-section $\mathbf{a}_{4}$ and $\mathbf{L}_{\mathbf{b}}=0.5 \mathrm{~m}$ the distance between $\mathbf{b}_{3}$ and the new cross-section $\mathbf{b}_{4}$ (Figure 7).

Measuring the cross-spectrum matrix between microphones in the four crosssections $\mathbf{a}_{1}, \mathbf{b}_{3}, \mathbf{a}_{\mathbf{4}}$ and $\mathbf{b}_{\mathbf{4}}$ given by $\left[\mathbf{G}^{\prime}\right]$, the source modal cross-spectrum matrix in sections $\mathbf{a}_{\mathbf{1}}$ and $\mathbf{b}_{\mathbf{3}}$ can be estimated from Equation [18].

$$
\begin{aligned}
& {\left[\mathbf{G}^{\prime}\right]_{2 \mathbf{M} \times \mathbf{2} \mathbf{M}}=\left[\begin{array}{ll}
{\left[\mathbf{G}_{\mathbf{a}_{1} \mathbf{a}_{4}}\right]_{\mathbf{M} \times \mathbf{M}}} & {\left[\mathbf{G}_{\mathbf{b}_{3} \mathbf{a}_{4}}\right]_{\mathbf{M} \times \mathbf{M}}} \\
{\left[\mathbf{G}_{\mathbf{a}_{1} \mathbf{b}_{4}}\right]_{\mathbf{M} \times \mathbf{M}}} & {\left[\mathbf{G}_{\mathbf{b}_{3} \mathbf{b}_{4}}\right]_{\mathbf{M} \times \mathbf{M}}}
\end{array}\right]_{2 \mathbf{M} \times 2 \mathbf{M}}} \\
& {\left[\mathbf{G}^{\mathbf{s}}\right]_{2 \mathbf{N} \times 2 \mathbf{N}}=\left[\mathbf{T}^{-}\right]_{2 \mathbf{N} \times 2 \mathbf{N}} \cdot\left[\mathbf{C}^{\prime}\right]_{2 \mathbf{N} \times 2 \mathbf{M}} \cdot\left[\mathbf{G}^{\prime}\right]_{2 \mathbf{M} \times 2 \mathbf{M}} \cdot[\mathbf{C}]_{2 \mathbf{M} \times 2 \mathbf{N}}^{\mathrm{c}}}
\end{aligned}
$$

where:

$$
\left[\mathbf{C}^{\prime}\right]_{2 \mathrm{~N} \times 2 \mathrm{M}}=\left[[\mathrm{I}]-\left[\mathbf{S}^{\prime}\right] \cdot\left[\mathbf{R}^{\prime}\right]\right]_{2 \mathrm{~N} \times 2 \mathrm{~N}} \cdot\left[\Pi^{\prime}\right]_{2 \mathrm{~N} \times 2 \mathrm{M}}
$$

$-\left[\mathbf{S}^{\prime}\right]_{2 \mathbf{N} \times 2 \mathbf{N}}=\left[\mathbf{T}^{-}\right]_{2 \mathbf{N} \times 2 \mathbf{N}}^{-1} \cdot[\mathbf{S}]_{2 \mathbf{N} \times 2 \mathbf{N}} \cdot\left[\mathbf{T}^{+}\right]_{2 \mathbf{N} \times 2 \mathbf{N}}$ represent the scattering matrix computed at the cross-sections $\mathbf{a}_{4}$ and $\mathbf{b}_{4}$.

$-\left[\mathbf{R}^{\prime}\right]_{2 \mathrm{~N} \times 2 \mathrm{~N}}=\left[\mathbf{T}^{+}\right]_{2 \mathrm{~N} \times 2 \mathrm{~N}}^{-1} \cdot[\mathbf{R}]_{2 \mathrm{~N} \times 2 \mathrm{~N}} \cdot\left[\mathbf{T}^{-}\right]_{2 \mathrm{~N} \times 2 \mathrm{~N}}$ is the reflection matrix of the terminations computed at the cross-sections $\mathbf{a}_{\mathbf{4}}$ and $\mathbf{b}_{\mathbf{4}}$.

$-\left[\Pi^{\prime}\right]_{2 \mathrm{~N} \times \mathbf{2 M}}$ is obtained by transforming the matrix $[\Pi]_{2 \mathrm{~N} \times \mathbf{2 M}}$ from the crosssections $\mathbf{a}_{\mathbf{1}} \mathbf{b}_{3}$ to $\mathbf{a}_{\mathbf{4}} \mathbf{b}_{\mathbf{4}}$.

$-\left[\mathbf{T}^{+}\right]_{2 \mathbf{N} \times \mathbf{2 N}},\left[\mathbf{T}^{-}\right]_{2 \mathbf{N} \times \mathbf{2 N}}$ are the propagation matrices from $\mathbf{a}_{1} \mathbf{b}_{3}$ to $\mathbf{a}_{4} \mathbf{b}_{4}$.

$$
\begin{aligned}
& {\left[\mathbf{T}^{-}\right]_{2 \mathrm{~N} \times 2 \mathbf{N}}=\left[\begin{array}{cc}
{\left[\operatorname{diag}\left(\mathbf{e}^{\mathrm{i} \mathbf{K}_{\mathrm{mn}}^{-} \mathbf{L}_{\mathrm{a}}}\right)\right]_{\mathrm{N} \times \mathbf{N}}} & {[\mathbf{0}]_{\mathrm{N} \times \mathbf{N}}} \\
{[0]_{\mathrm{N} \times \mathbf{N}}} & {\left[\operatorname{diag}\left(\mathbf{e}^{-i K_{\mathrm{mn}}^{+} \mathbf{L}_{\mathbf{b}}}\right)\right]_{\mathrm{N} \times \mathbf{N}}}
\end{array}\right]_{2 \mathbf{N} \times 2 \mathrm{~N}} ;}
\end{aligned}
$$

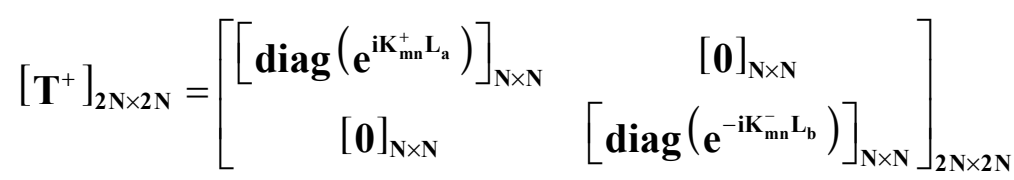




\section{The numerical approach}

Already, works on the modeling of duct scattering matrices have been carried out analytically (Poirier et al., 2009) or numerically (Taktak et al., 2010). In this works, the experiment is simulated by a numerical software IDEAS-RAYON VibroAcoustics (Hamdi et al., 1998) commercialized by ESIgroup.

The theoretical computation of the acoustic pressure produced by sources in the duct with anechoic terminations but without flow (Figure 8) is deduced from the formulation written as a system of four equations to solve:

$$
\left\{\begin{array}{l}
\Delta \mathbf{p}+\mathbf{k}^{2} \mathbf{p}=\mathbf{s}_{\mathbf{0}} \text { in } \Omega \\
\partial_{\mathbf{n}} \mathbf{p}=\mathbf{0} \text { on } \Gamma_{\mathbf{r}} \\
\partial_{\mathbf{n}} \mathbf{p}=-\mathbf{T}_{\mathbf{e}}(\mathbf{p}) \text { on } \Gamma_{\mathbf{e}} \\
\partial_{\mathbf{n}} \mathbf{p}=-\mathbf{T}_{\mathbf{s}}(\mathbf{p}) \text { on } \Gamma_{\mathbf{s}}
\end{array}\right.
$$

$\mathbf{p}$ is the acoustic pressure $\mathbf{p}=\mathbf{p}_{\mathbf{0}} \mathbf{e}^{\mathbf{i} \boldsymbol{t} t}, \mathbf{n}$ is the outside normal unit vector of the domain $\Omega$ (Figure 8). In [19], $\mathbf{s}_{\mathbf{0}}$ stands for a local pressure source located in the domain $\Omega, \Gamma_{\mathrm{r}}$ the perfectly rigid part of the surfaces and $\Gamma_{\mathrm{e}, \mathrm{s}}$ both artificial surfaces added in the numerical model to limit the computational domain $\Omega$ at the beginning and at the end of the rectangular guide as illustrated in Figure 8.

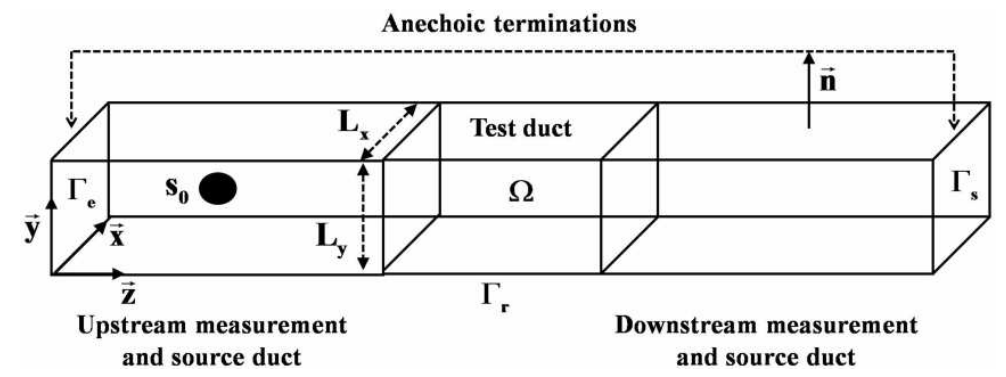

Figure 8. Model for the simulation

In the computations, we simulate only the part of the experimental set up located between both anechoic terminations.

In [19], $\mathbf{T}_{\mathbf{e}, \mathbf{s}}(\mathbf{p})$ are both Dirichlet to Neumann operators (DtN) modeling the transparent boundary conditions (Drissi, 2003 ; Bonnet et al., 2007) corresponding to the anechoic terminations in the experimental set up illustrated in Figure 4. To explicit these DtN operators, the transverse modal solution of the Helmholtz 
equation is used. In the particular case of the rectangular guide with perfectly rigid surfaces and without flow, these classic solutions $\Phi_{m \mathbf{n}}$ (Equation [3]) have been retained below.

The DtN operators $\mathbf{T}_{e, s}(\mathbf{p})$ on $\Gamma_{\mathrm{e}, \mathrm{s}}$ are also given by:

$$
\mathbf{T}_{\mathrm{e}, \mathrm{s}}\left(\mathbf{p} \backslash \Gamma_{\mathrm{e}, \mathrm{s}}\right)= \pm \sum_{(\mathrm{m}, \mathrm{n})} \mathbf{i} \mathbf{K}_{\mathrm{mn}}^{ \pm} \mathbf{p}_{\mathrm{mn}}^{ \pm} \Phi_{\mathrm{mn}}(\mathbf{x}, \mathbf{y})
$$

where

$$
\mathbf{p}_{\mathrm{mn}}^{ \pm}=\int_{\Gamma_{\mathrm{e}, s}} \mathbf{p}(\mathbf{x}, \mathbf{y}, \mathbf{z}) \Phi_{\mathrm{mn}}(\mathbf{x}, \mathbf{y}) \mathbf{d} \Gamma
$$

and $\mathbf{K}_{\mathrm{mn}}^{ \pm}$is given by Equation [4] for $\mathbf{M}=\mathbf{0}$.

\section{Finite element discretization}

Thanks to the introduction of both $\Gamma_{\mathrm{e}, \mathrm{s}}$ artificial surfaces, the computational domain is bounded. So, it becomes possible to employ a Finite Element Method to solve the system of Equations [19].

The variational formulation of this system provides the following problem:

$$
\begin{aligned}
& \text { find } \mathbf{p} \in \mathbf{H}^{1}(\Omega) / \forall \mathbf{p}^{\prime} \in \mathbf{H}^{1}(\Omega) \text {, } \\
& -\mathbf{H}\left(\mathbf{p}, \mathbf{p}^{\prime}\right)+\mathbf{k}^{2} \mathbf{Q}\left(\mathbf{p}, \mathbf{p}^{\prime}\right) \\
& +\left(\sum_{(\mathbf{m}, \mathbf{n})} \mathbf{K}_{\mathrm{mn}}^{+} \mathbf{C}_{\Gamma_{\mathrm{e}}}\left(\mathbf{p}, \Phi_{\mathrm{mn}}\right) \mathbf{C}_{\Gamma_{\mathrm{e}}}\left(\Phi_{\mathrm{mn}}, \mathbf{p}^{\prime}\right)\right) \\
& +\left(\sum_{(\mathbf{m}, \mathbf{n})} \mathbf{K}_{\mathrm{mn}}^{-} \mathbf{C}_{\Gamma_{\mathrm{s}}}\left(\mathbf{p}, \Phi_{\mathrm{mn}}\right) \mathbf{C}_{\Gamma_{\mathrm{s}}}\left(\Phi_{\mathrm{mn}}, \mathbf{p}^{\prime}\right)\right)=\mathbf{C}_{\Omega}\left(\mathbf{s}_{\mathbf{0}}, \mathbf{p}^{\prime}\right)
\end{aligned}
$$

where

$$
\mathbf{H}\left(\mathbf{p}, \mathbf{p}^{\prime}\right)=-\int_{\Omega} \nabla \mathbf{p} \cdot \nabla \mathbf{p}^{\prime} \mathbf{d} \Omega ; \mathbf{Q}\left(\mathbf{p}, \mathbf{p}^{\prime}\right)=-\int_{\Omega} \mathbf{p} \cdot \mathbf{p}^{\prime} \mathbf{d} \Omega
$$

and

$$
\mathbf{C}_{\Gamma}\left(\Phi_{\mathrm{mn}}, \mathbf{p}^{\prime}\right)=\int_{\Gamma} \mathbf{p}^{\prime} \Phi_{\mathrm{mn}} \mathrm{d} \Gamma ; \mathbf{C}_{\Omega}\left(\mathbf{s}_{\mathbf{0}}, \mathbf{p}^{\prime}\right)=\int_{\Omega} \mathbf{s}_{\mathbf{0}} \mathbf{p}^{\prime} \mathbf{d} \Omega
$$

By discretization using volumic second order finite element, the previous expression [22] provides the following matrix problem: 


$$
\left[\begin{array}{rl}
\mathbf{H}+\mathbf{k}^{2} \mathbf{Q} & +\sum_{(\mathbf{m}, \mathbf{n})} \mathbf{K}_{\mathbf{m n}}^{+} \mathbf{C}_{\Gamma_{\mathrm{e}}}\left\{\Phi_{\mathbf{m n}}\right\}\left\{\Phi_{\mathbf{m n}}\right\}^{\mathrm{T}} \mathbf{C}_{\Gamma_{\mathrm{e}}} \\
& +\sum_{(\mathbf{m}, \mathbf{n})} \mathbf{K}_{\mathrm{mn}}^{-} \mathbf{C}_{\Gamma_{\mathrm{s}}}\left\{\Phi_{\mathbf{m n}}\right\}\left\{\Phi_{\mathbf{m n}}\right\}^{\mathrm{T}} \mathbf{C}_{\Gamma_{\mathrm{s}}}
\end{array}\right]\{\mathbf{p}\}=\mathbf{C}_{\Omega}\left\{\mathbf{s}_{\mathbf{0}}\right\}
$$

where $\{\mathbf{p}\}$ represent the nodal values vector of the computed pressure.

The final linear system [23] is solved by using the MUMPS library based on a multi-frontal approach which performs a direct factorization LU or LDLT depending on the symmetry of the matrix (Amestoy et al., 2009).

The numerical scattering matrix calculation is therefore deduced by calculating the pressure produced at the same locations as measured by the microphones by twenty monopole type sources located at the same location as the loudspeakers in the experiment and following the experimental flow data treatment shown in Figure 6.

\section{Results with a diaphragm}

All results are plotted versus frequency up to $3500 \mathrm{~Hz}$ where a maximum of $\mathbf{N}$ $=10$ propagating modes are considered in the duct. Some typical experimental and numerical results of the no flow diaphragm scattering matrix coefficient spectra are compared. Then experimental results with flow of the scattering matrix coefficient spectra and of the source spectra generated by flow diaphragm interaction are discussed.

The diaphragm is located at the center of the rectangular waveguide whose the $\mathbf{L}_{\mathbf{x}} \times \mathbf{L}_{\mathbf{y}}$ cross-section is $0.2 \mathrm{~m} \times 0.1 \mathrm{~m}$. The inner $\mathbf{L}_{\mathbf{1 x}} \times \mathbf{L}_{\mathbf{1 y}}$ cross-section of the diaphragm is $0.1 \mathrm{~m} \times 0.056 \mathrm{~m}$ and its thickness $\mathbf{e}$ is $0.004 \mathrm{~m}$ as illustrated in Figure 9 .

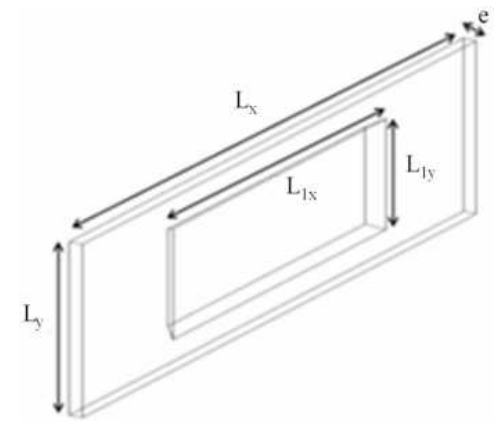

Figure 9. Characteristic dimensions of the diaphragm 


\subsection{The no-flow case}

A volumic second order finite element is used to discretize the geometric model of the diaphragm. The mesh size is fixed to $\lambda_{\max } / \mathbf{5}$ as shown in Figure 10.

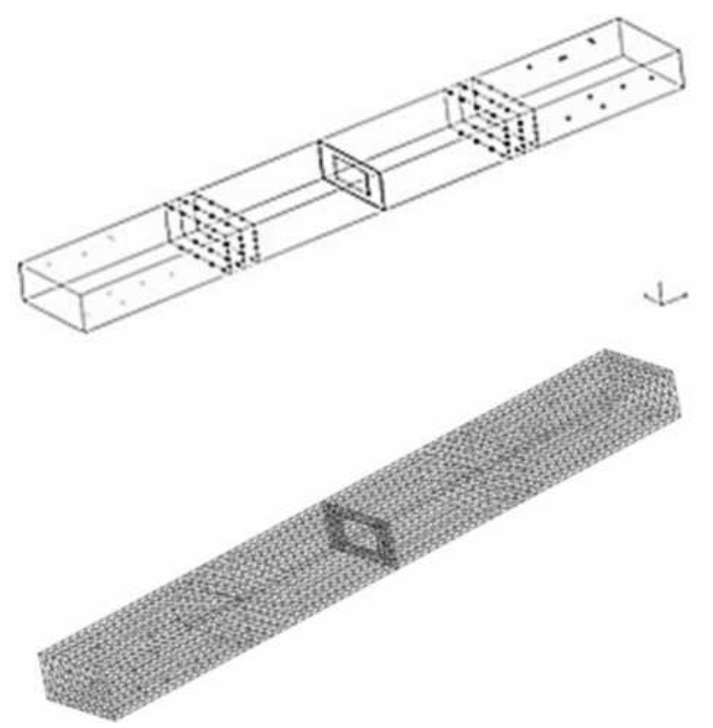

Figure 10. Finite element model of the diaphragm

In Figure 11 a very good agreement is shown between numerical and experimental reflection and transmission coefficient spectra of the plane wave mode $(\mathbf{0 , 0 )}$ for the diaphragm in the no-flow case.

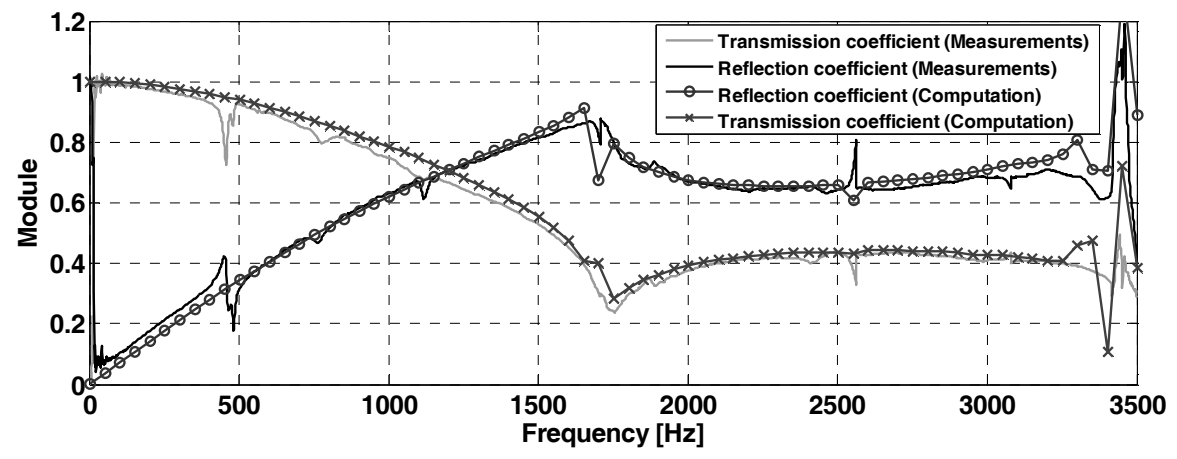

Figure 11. Comparison between theoretical and experimental results of the reflection and transmission coefficients of the diaphragm for the plane wave mode $(0,0)$ in the no-flow case 
As shown in Figure 12, the agreement between experiment and theory is also very good on the reflection and transmission coefficients spectra for the first higher order mode $\mathbf{( 0 , 1 )}$ which is cut-on at $853.3 \mathrm{~Hz}$.

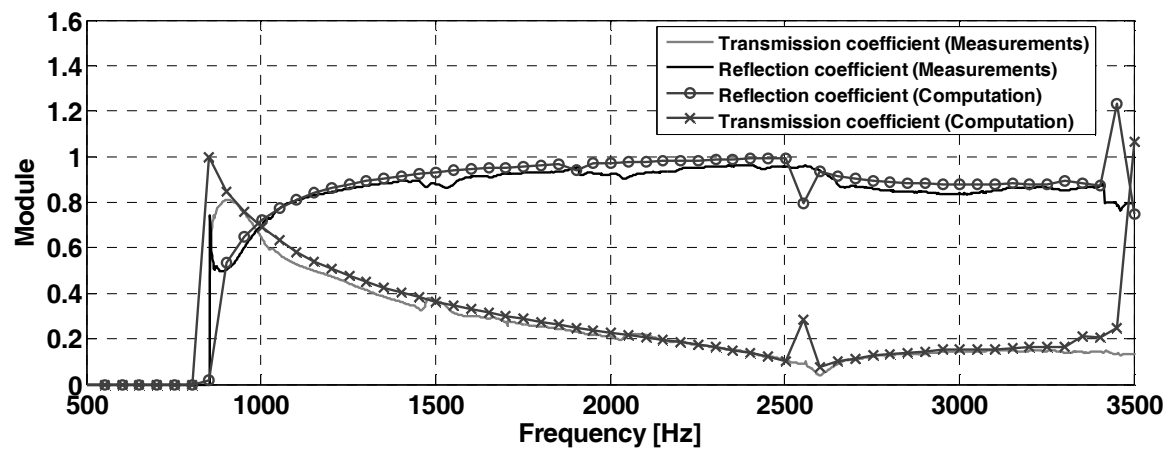

Figure 12. Comparison between theoretical and experimental results of the reflection and transmission coefficients of the diaphragm for the mode $(0,1)$ in the no-flow case

Figure 13 shows a comparison between theoretical and experimental results of the transmission modal conversion coefficient spectrum from the first mode $\mathbf{( 0 , 0 )}$ to the third higher order mode $(\mathbf{0 , 2})$. The agreement is still very good.

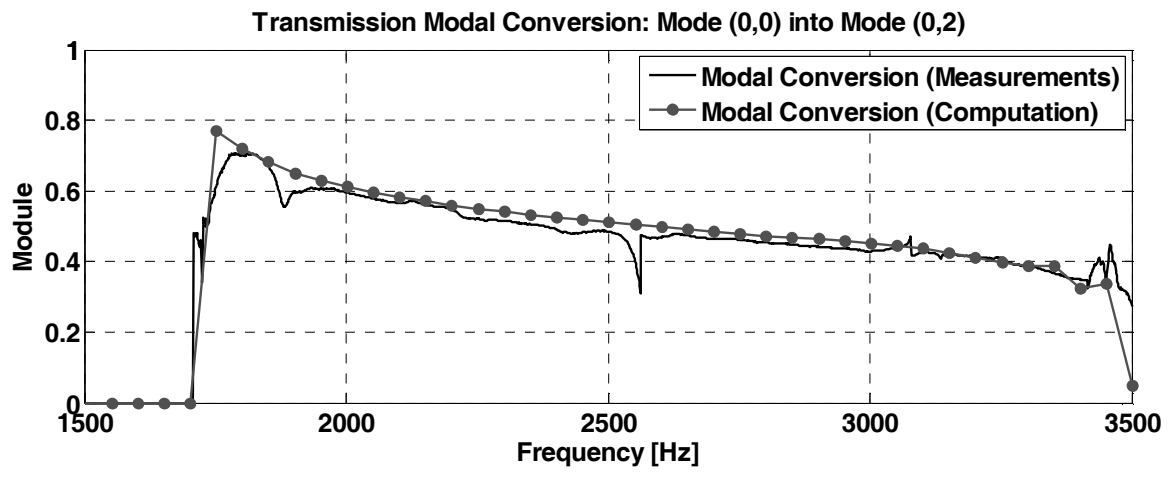

Figure 13. Comparison between theoretical and experimental results of the conversion transmission coefficient of the diaphragm for the first mode $(0,0)$ into mode $(0,2)$ in the no-flow case

The transmission and refection modal conversion occurs only between the modes which have an even horizontal indice $\mathbf{n}$ such as modes $(\mathbf{0 , 0}),(\mathbf{0 , 2})$ and $(\mathbf{0}, \mathbf{4})$. This is 
pointed out in Figure 14 where the transmission modal conversion between the modes $(\mathbf{0 , 0})$ and $(\mathbf{0 , 1})$ is close to zero.

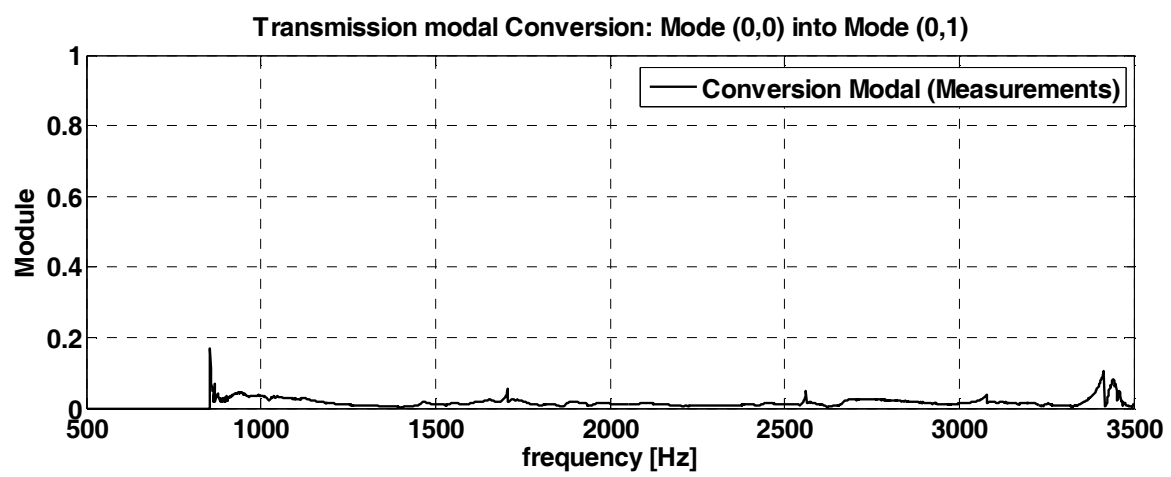

Figure 14. Transmission modal conversion coefficient of the first mode $(0,0)$ into the first higher order mode $(0,1)$ for the diaphragm in the no-flow case

\subsection{The uniform flow case}

The experiment is conducted with $11.8 \mathrm{~m} \cdot \mathrm{s}^{-1}$ uniform flow speed and a mean temperature equal to $17.3^{\circ} \mathrm{C}$.

Figure 15 and Figure 16 shows the effect of the flow respectively on the transmission and reflection coefficient spectra of the plane waves propagating upstream and downstream.

Without flow the transmission coefficient spectra of the plane waves propagating upstream $\mathbf{S}_{\mathbf{0 0 , 0 0}}^{12}$ and downstream $\mathbf{S}_{\mathbf{0 0 , 0 0}}^{\mathbf{2 1}}$ are very close. Small differences are due to the transversal shape of the diaphragm as shown in Figure 7. The effect of flow on the transmission spectra is evident in Figure 15 pointing out the convection effect which leads to different coefficients depending upon the direction of propagation versus the flow. The value of the coefficient $\mathbf{S}_{\mathbf{0 0 , 0 0}}^{\mathbf{2 1}}$ is lower in the whole frequency domain than this of the no flow case when the wave propagates in the direction of the flow. $\mathbf{S}_{\mathbf{0 0 , 0 0}}^{12}$ is higher above the cut-on frequency of the third and the fourth higher order modes $\left(\mathbf{f}_{\mathbf{c}(0,2)}\right.$ $=\mathbf{f}_{\mathbf{c}(1,0)}=1704 \mathrm{~Hz}$ ) when the wave propagates against the flow.

The convection effect is also evident on the curves in Figure 16 presenting the reflection coefficient spectra.

These results have been already pointed out by Hofmans (Hofmans et al., 2001) and Durrieu (Durrieu et al., 2001) in the low frequency range. 


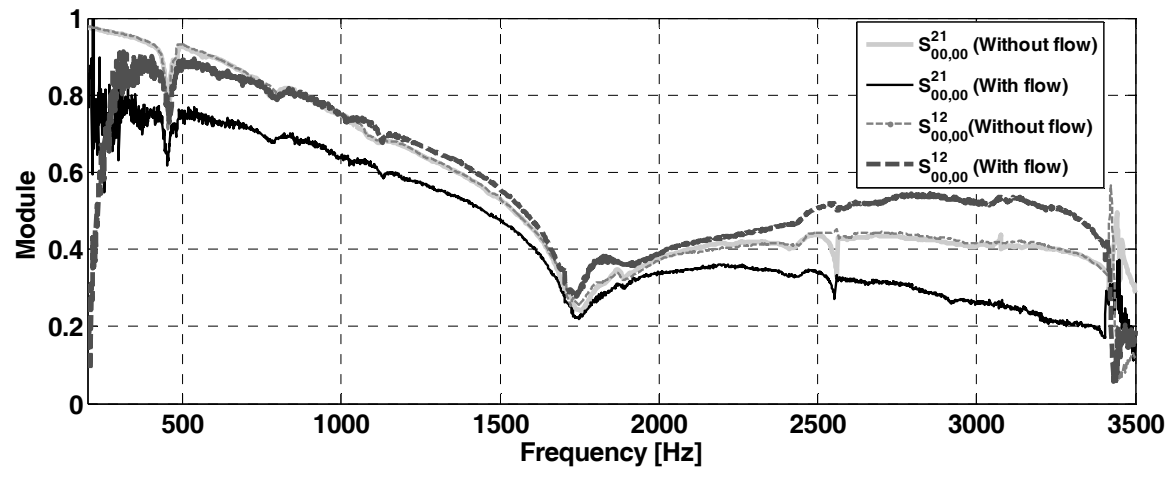

Figure 15. Flow effect on the transmission coefficient of the mode $(0,0)$ for the diaphragm

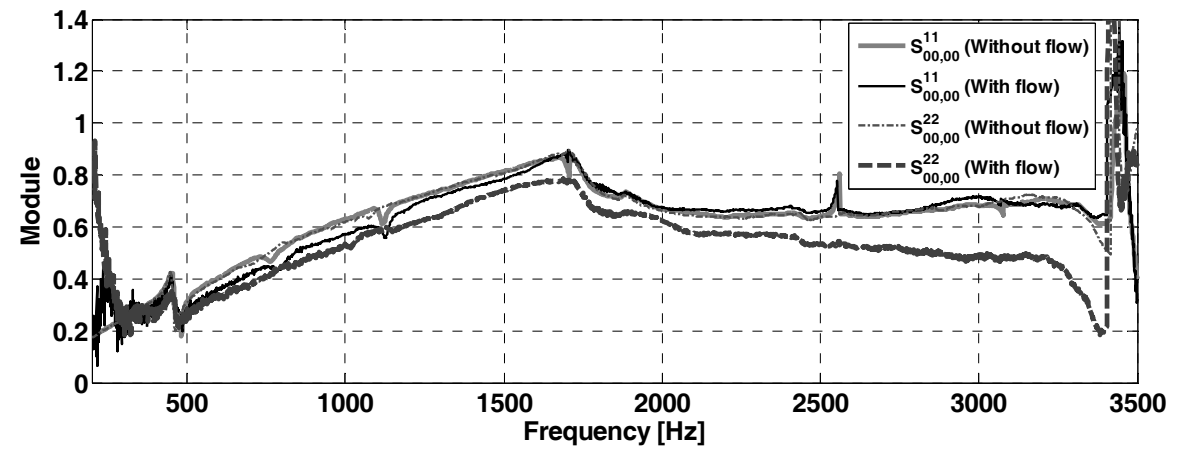

Figure 16. Flow effect on the reflection coefficient of the mode (0,0) for the diaphragm

In Figure 7 the first components of the source modal cross-spectrum matrix are plotted. They represent the source strength spectrum measured on the upstream and downstream sides of the diaphragm for the mode $\mathbf{( 0 , 0 )}$. This spectrum was estimated by the use of the close cross-sections $\mathbf{a}_{\mathbf{1}}$ and $\mathbf{b}_{\mathbf{3}}$ on each side of the diaphragm (Figure 7). The level of sound generated by the interaction between the flow and the diaphragm on the downstream part is shown to be higher than the level on the upstream part. This is due to the effect of the local turbulence on the microphones which can be avoided if the estimation of the source strength level is performed with two other measurement cross-sections, as mentioned in section 3.3 and shown below. 


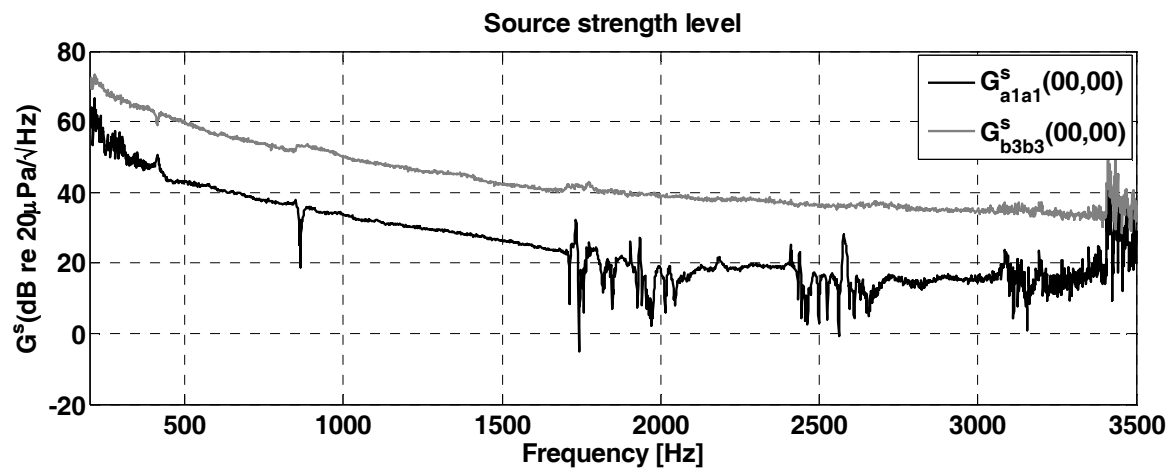

Figure 17. Source strength level on the upstream and downstream side of the diaphragm with the use of only one cross-section on each side of the diaphragm: Mode $(0,0)$

Indeed, in Figure 18 an estimation of the source strength level on the upstream and downstream side of the diaphragm is achieved with two cross-sections on each side of the diaphragm (" $\mathbf{a}_{\mathbf{1}}, \mathbf{a}_{\mathbf{4}}$ " on the downstream and " $\mathbf{b}_{\mathbf{3}}, \mathbf{b}_{\mathbf{4}}$ " on the upstream, Figure 7). Presented results point out that the level of sound generated by the interaction between the flow and the diaphragm is the same upstream and downstream the diaphragm which shows the dipole source character of the diaphragm for the low Mach number (Allam et al., 2006). The spectrum is dominated by frequencies lower than $800 \mathrm{~Hz}$ where only the plane wave propagates.

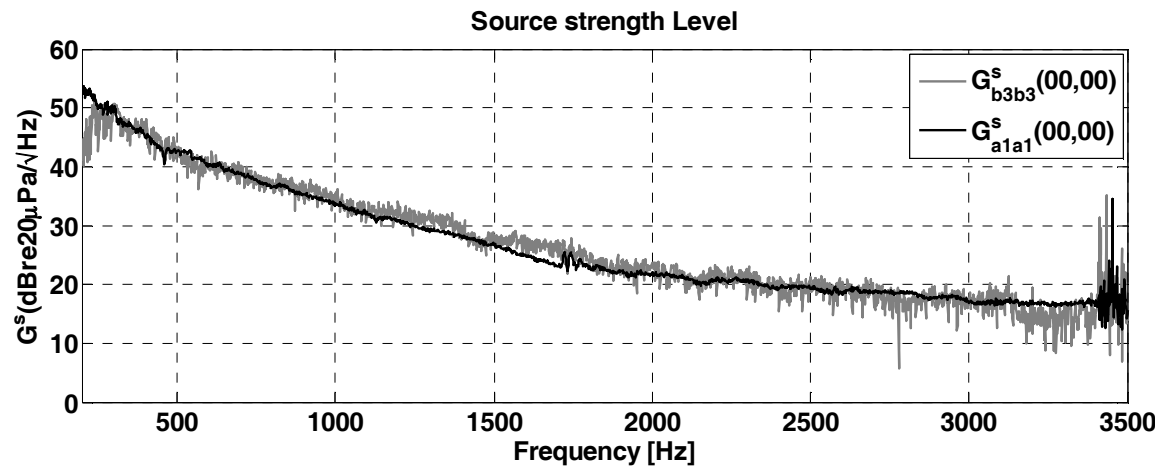

Figure 18. Source strength level on the upstream and downstream side of the diaphragm with the use of two measurement cross-sections on each side of the diaphragm: Mode $(0,0)$ 


\section{Summary and conclusions}

In this work, an experimental method that provides the passive and active acoustic properties of an obstacle has been presented. This method consists of two steps. First, the passive properties, described by the multimodal scattering matrix $[\mathbf{S}]$, of the diaphragm are measured by using a movable external source which generates an acoustic field uncorrelated with the field from the source under test. During this step, the reflection matrix $[\mathbf{R}]$, which contains reflection data of the upstream and downstream terminations, is also obtained. In the second step, the active properties of the diaphragm are deduced from the estimation of the source strength matrix $\left[\mathbf{G}^{\mathbf{s}}\right]$. In order to suppress the influence of flow disturbance in the determination of the source strength matrix, a correlation technique, suggested by Aböm (Aböm et al., 1992) and based on measurements at two cross-sections on each side of the obstacle, is used.

A 3D-FEM Method has been developed and integrated on the IDEAS-RAYON Vibro-Acoustics software to simulate the experiment in the no flow case. The results of the scattering matrix coefficient spectra of the duct section including the diaphragm show a very good agreement between the numerical simulation and the experiment validating the experimental procedure.

The results of the measurement of the scattering matrix coefficient spectra of the diaphragm with flow point out the convection effect which modify the transmission and reflection coefficients depending on the direction of the wave propagation versus the flow.

As expected the source strength levels on the upstream and the downstream side of the diaphragm are found to be similar at low Mach number.

The flow facility is now used to measure the aero-acoustic properties of automotive air conditioning elements.

In the future, the numerical model will be extended to the flow configuration including the aero-acoustic source calculation. Also an interesting way of research is the coupling between experiment and numerical computation in order to achieve a design software to predict the complete behavior of air conditioning network.

\section{Acknowledgments}

This work was realized within the framework of "Pôle de Compétitivité I-TranS - Région Nord Pas de Calais Pïcardie" through the project REVA-CESAM coordinated by Valeo Thermique Habitacle. 


\section{References}

Aböm M., Bodèn H., Lavrentjev J., "Source characterization of fans using acoustic 2-port models", Proceedings of fan Noise 92, France, 1992, p. 359-364.

Allam S., Aböm M., “Advanced experimental procedure for in-duct aero-acoustics”, ICSV13, Vienna, 2-6 July 2006, Austria.

Amestoy P.-R., Duff I.-S., Koster J., L'Excellent J.-Y., Pralet S., MUltifrontal Massively Parallel Solver, MUMPS 4.9, User's guide CERFACS, ENSEEIHT, 2009.

Bonnet-Ben Dhia A.S., et al.,. «Condition aux limites transparente pour la propagation acoustique dans un guide recouvert d'un matériau absorbant en présence d'écoulement uniforme », $18^{e}$ Congrees of mecanic, Grenoble, France, 2007.

Drissi D., Simulation des silencieux d'échappement par une méthode d'éléments finis homogénéisée, Thèse de doctorat, Université de Tunis, 2003.

Durrieu D., Hofmans G., Ajello G., Boot R., Aurégan Y., Hirschberg A., Peters M., "Quasisteady aero-acoustic response of orifices", J. Acoust. Soc. Am, vol. 110, n 4, 2001, p. 517-531.

Hamdi M.A., Mebarek L., User’s guide for RAYON-Ideas Vibro-Acoustic, 1998.

Hofmans G., Ranucci M., Ajello G., Aurégan Y., Hirschberg A., “Aeroacoustic response of a slit-shaped diaphragm in a pipe at low Helmholtz number, 2: Unsteady results", Journal of Sound and Vibration, vol. 244, $\mathrm{n}^{\circ} 1,2001$, p. 57-77.

Hofmans G., Boot R., Durrieu D., Aurégan Y., Hirschberg A., "Aeroacoustic response of a slit-shaped diaphragm in a pipe at low Helmholtz number, 1: Quasi-steady results", Journal of Sound and Vibration, vol. 244, $\mathrm{n}^{\circ}$ 1, 2001, p. 35-56.

Lavrentjev J., Aböm M. "Characterisation of fluid machines as acoustic multi-port sources", Journal of Sound and Vibration, vol. 197, n 1, 1996, p. 1-16.

Lavrentjev J., Aböm M., Bodèn H., "A measurement method for determining the source data of acoustic two-port sources", Journal of Sound and Vibration, vol. 183, $\mathrm{n}^{\circ}$ 3, 1995, p. 517-531.

Poirier B., Ville J.M., Maury C., Kateb M.E., "Bicylindrical model of HQ tube duct system: Theory and comparison with experiment and finite element method", J. Acoust. Soc. Am, vol. $126, \mathrm{n}^{\circ} 3,2009$, p. 1151-1162.

Sitel A., Ville J.-M., Foucart F., "Multiload procedure to measure the acoustic scattering matrix of a duct discontinuity for higher order mode propagation conditions", J. Acoust. Soc. Am, vol. 120, n 5, 2006, p. 2478-2490.

Taktak M., Mesure de la matrice de diffusion d'un tronçon traité cylindrique: applications à la mesure de son éfficacité et à la détermination de son impédance homogénéisée, Thèse de doctorat, Université de Technologie de compiègne, 2008.

Taktak M., Ville J.M., Haddar M., Gabard G., Foucart F. “An indirect method for the characterization of locally reacting liners", J. Acoust. Soc. Am, vol. 127, n ${ }^{\circ}$ 6, 2010, p. 3548-3559. 
